\title{
Exploring the Role of Heavy Metals and Their Derivatives on the Pathophysiology of COVID-19
}

\author{
Ali Bahrami ${ }^{1,2} \cdot$ Mohammad Reza Arabestani $^{3} \cdot$ Mohammad Taheri $^{3} \cdot$ Abbas Farmany $^{4} \cdot$ Fatemeh Norozzadeh $^{1,2}$. $^{2}$ \\ Seyed Mostafa Hosseini ${ }^{3} \cdot$ Hesam Nozari $^{1,2} \cdot$ Fatemeh Nouri $^{2}(0$
}

Received: 3 May 2021 / Accepted: 17 August 2021 / Published online: 27 August 2021

(c) The Author(s), under exclusive licence to Springer Science+Business Media, LLC, part of Springer Nature 2021

\begin{abstract}
Many aspects of the severe acute respiratory syndrome coronavirus 2 (SARS-CoV-2) and its disease, COVID-19, have been studied to determine its properties, transmission mechanisms, and pathology. These efforts are aimed at identifying potential approaches to control or treat the disease. Early treatment of novel SARS-CoV-2 infection to minimize symptom progression has minimal evidence; however, many researchers and firms are working on vaccines, and only a few vaccines exist. COVID-19 is affected by several heavy metals and their nanoparticles. We investigated the effects of heavy metals and heavy metal nanoparticles on SARS-CoV-2 and their roles in COVID-19 pathogenesis. AgNPs, AuNPs, gold-silver hybrid NPs, copper nanoparticles, zinc oxide, vanadium, gallium, bismuth, titanium, palladium, silver grafted graphene oxide, and some quantum dots were tested to see if they could minimize the severity or duration of symptoms in patients with SARS-CoV-2 infection when compared to standard therapy.
\end{abstract}

Keywords Heavy metals $\cdot$ COVID-19

\section{Introduction}

Since December 2019, the coronavirus infection disease 2019 (COVID-19), caused by a new form of coronavirus known as severe acute respiratory syndrome coronavirus 2 (SARS-CoV-2), has spread around the world, killing thousands of people. Due to the rapid spread and ability of genetic mutations, and mortality from them, they have always been a major challenge for healthcare systems [1]. SARS-CoV-2 has 40 different strains and has created a worrying situation in the world [2]. This virus belongs to the family of SSRNA viruses and has four genera: alpha, beta,

Fatemeh Nouri

Fatemenouri1@gmail.com

1 Student Research Committee, Hamadan University of Medical Sciences, Hamadan, Iran

2 Department of Pharmaceutical Biotechnology, School of Pharmacy, Hamadan University of Medical Sciences, Hamadan, Iran

3 Department of Medical Microbiology, Faculty of Medicine, Hamadan University of Medical Sciences, Hamadan, Iran

4 Dental Research Center, Hamadan University of Medical Sciences, Hamadan, Iran gamma, and delta. Alpha and beta genus usually infect mammals, including humans [3], Unlike delta and gamma, which mainly infect birds [4]. In all of them, there are four types of proteins called spike (S), envelope (E), membrane (M), and nucleocapsid (N) [5]. Only protein $\mathrm{S}$ can bind to the receptors [6, 7] Although reports indicate that SARS-CoV-2 is more than $80 \%$ similar to the SARS genome and $50 \%$ similar to MERS, unfortunately, the SARS-CoV-2 transmission rate is much higher, but the resulting mortality rate is lower. Also, unlike SARS-CoV and MERS-CoV, which are more common in the hospital environment, SARS-CoV-2 is more prevalent in the community. The main SARS-CoV and SARS-CoV-2 receptors are both, ACE2, but the SARS$\mathrm{CoV}-2$ connection to the receptors is significantly faster $(10$ times). The main site of SARS-CoV-2 proliferation is the lungs, and after targeting the lungs, it damages the epithelium and causes inflammation. Cytokine secretion causes respiratory distress syndrome and multiple organ failure. Lymphopenia occurs in $81 \%$ of patients. There is also a decrease in platelets and albumin levels and an increase in aminotransferases, lactic dehydrogenase, keratin kinase, and CRP levels in COVID-19 patients. Acute respiratory distress syndrome occurs in $32.8 \%$ of patients, and acute heart damage occurs in $13 \%$, which is a dangerous statistic 
[3]. The disease primarily causes damage to the upper respiratory tract and gastrointestinal tract [8]. Symptoms can vary depending on the degree of infection. These symptoms include respiratory problems, fever, cough, diarrhea, shortness of breath, and kidney failure [9]. Although COVID-19 threatens everyone, there is a higher risk for people with chronic obstructive pulmonary disease, obesity, cancer, smoking, immunodeficiency [10], hypertension, diabetes, respiratory disorders, and heart disease and they are more sensitive, so they need more health care. According to reports [11, 12], COVID-19 patients have a median age of 51.2 years, with males accounting for $55.9 \%$ of cases. The incubation period of the disease is 3 to 7 days. Diagnosis of coronavirus is by samples such as nasal swabs, nasopharyngeal or tracheal extract, sputum or lung tissue, and blood or feces of patients [13]. The laboratory diagnostic method is applied by the detection of nucleic acid by the reverse transcription-quantitative polymerase chain reaction. Despite many efforts, there is no definitive cure for this disease [3]. To provide treatment to patients, we need to use the currently approved drugs. But these available antiviral drugs are only a temporary solution, and definitely it will take some time for targeted therapies for the virus to be tested and reach the point of mass use by the general public. Vaccination is the only treatment that both strengthens the immune system and increases the number of antibodies [14].

Today, nanoparticles have entered the field of corona control as an important issue [15], especially since the virus has a diameter of 60 to $140 \mathrm{~nm}$, which is only slightly larger than nanoparticles, and this similarity in diameter is very beneficial [6]. The small size of the nanoparticles helps them to enter [1]. Nanoparticles are a new therapeutic approach and have attractive properties such as small size, specific shape, adjustable surface charge, paramagnetic cloud, photon conversion, bioavailability, biocompatibility, tolerance, and biodegradability and adaptability [16-18]. In addition, these nanoparticles can cross the blood-brain barrier and the blood-air barrier. Stable and targeted controlled secretion is also possible with them. Nanomedicine is involved in all areas of medicine. In gene delivery, artificial implants, immunoassays, biosensors, cancer treatment or diagnosis, imaging, nanotherapy, vaccine and biological material production, and targeted drug delivery are used. Nanoparticles have antimicrobial effects. Although their antiviral effects have not been conclusively proven, hopes are still high, and scientists are studying it. Nanoparticles consisting of titanium, silver, gold, and zinc have previously been shown effective against HIV, influenza, herpes simplex, RSV, and smallpox, and zikavirus [1, 12, 19-22].

Elemental heavy metals and their salts or complexes also have many effects on the body and disease. Inhibition of viral RNA synthesis, prevention of virus binding to cells and its entry $[1,6,23]$, improving the inflammatory responses
[22, 24], inhibiting the viral replication [25, 26], stimulating and activating $T$ cells [27], and inhibiting helix unwinding and ATPase activity of SARS-CoV-2 nsp13 [27] are some of the effects of heavy metals and their salts or nanoparticles on COVID-19. This study was aimed to review recent SARSCoV-2 research to outline heavy metals and their derivative on the pathophysiology of COVID-19.

\section{Method}

The bibliographic search was performed on PubMed, Scopus, and Web of Science databases on February 4, 2021. Search keywords including "Arsenic" OR "Bismuth" OR "Cadmium" OR "Chromium" OR "Gallium" OR "Mercury" OR "Nickel" OR "Palladium" OR "Pb" OR "Silver" OR "Thallium" OR "Tin" OR "Titanium" OR "Vanadium" OR "Gold” OR "Metals" AND “coronavirus 2019" OR "COVID-19" OR "SARSCoV-2" in all fields. Any languages or date restrictions were not applied. Identified studies were screened by title, abstract, and full text. The reference list of identified studies was also evaluated to increment the sensitivity and choice of most literature, which we could not identify in the database. Initiate with most excellent sensitivity search found the number of 167 articles on external databases, and collected by a researcher using Endnote software. Then unifying the articles from all the cited databases and bringing out duplicate articles, the two researchers separately investigated all the articles and excluded the articles that were not related to the topic and the inclusion index criteria. Afterward, several articles after reviewing titles and abstracts were excluded. The extant articles were cautiously evaluated, and the relevant study was selected. The data for the studies, based on the title, examined method, sample size, etc., were evaluated. Finally, after obtaining related articles and limitations of search strategy, 100 articles were analyzed. During the reviewed articles in 2021, if we identified a new article, we would include it in our study.

\section{Results}

\section{Selenium Nanoparticles and Ebselen}

In the previous study [28], we discussed the level of selenium and its involvement in COVID-19. There is relativity between selenium level and COVID-19 cure rate. Patients with a higher level of selenium in their hair samples had a higher cure rate than patients with a lower amount of selenium. And it has been observed that patients who survived from COVID-19 had a higher level of selenium in their serum [29-34]. So we hypothesized that a higher intake of $\mathrm{Se}$ can lead to a higher cure rate in COVID-19. Selenium can 
boost the immune system by enhancing the role of natural killer cells and $\mathrm{T}$ lymphocytes. Also, it has shown some antiviral activities [35]. The main consideration of selenium is its toxicity in high doses. Selenium has different forms but nano-selenium has lower toxicity and higher bioavailability and efficiency in preventing oxidative damage [36-39]. Also, selenium nanoparticles can be used in detection kits for SARS-CoV-2 [40]. Ebselen is an organic species of selenium. It has benefits in curing COVID-19; it can inhibit the COVID-19 virus through binding to the $\mathrm{M}^{\text {pro }}$ virion in the cell membranes [41]. Ebselen is a safe form of selenium and does not have toxicity which is observed in other forms of selenium and has the most efficacy at the concentration of $10 \mu \mathrm{M}$ against COVID-19. Also, hepatic damages that have been observed in patients infected with COVID-19 can be inhibited by ebselen [42-46].

\section{Iron Oxide Nanoparticles}

As we discussed in our last article in detail [28], the iron level of the body affects the COVID-19, so that abundant iron can increase viral infections. We observed that iron chelators may be beneficial because they reduce the iron level and it causes prevention in SARS-CoV-2 replication [47]. Now we will talk about the iron oxide nanoparticles. These nanoparticles are well biocompatible. Since they are presently used to treat anemia and are Food and Drug Administration (FDA) approved, they can be effectively produced on a large scale. In any case, for their antiviral effects, more tests ought to be done to get more exact data and make their use more secure and more useful [48]. The antiviral action of these nanoparticles is due to their binding to virus surface proteins. As a result, they interfere with the virus entering the cells. We know that SARS-CoV-2 must bind to the ACE2 receptor to enter the cells, which the spike protein in the virus is exceptionally vital in this process. Iron oxide nanoparticles attach to the coronavirus spike protein $[2,48]$. The $\mathrm{S} 1$ subunit has the receptor-binding domain (RBD) that makes the virus highly desirable to the receptor. The result of this attaching to spike protein is the inhibition of virus binding to the host receptors and thus the inhibition of the virus. These changes within the structure of the virus may be irreversible and the viral infection is reduced. Iron oxide nanoparticles can also be used within the generation of robes, masks, gloves, hospital fabrics, etc., to anticipate the spread of infection [48]. The docking study studied by Abozeid et al. found that interaction of iron oxide nanoparticles (IONPs) with S1-RBD results in the creation of the most stable complex, which is thought to be linked to viral protein conformational changes and hence impede virus entry into host cells. A clinical trial for FDA-approved IONPs for COVID-19 treatment has been authorized, as this binding could trigger virus elimination through the formation of reactive oxygen species [48].

\section{Silver Nanoparticles (AgNP)}

Many different inorganic nanomaterials have been studied to fight the coronavirus; the most effective are AGNPs, which act as potential antiviral agents as well as drug carriers [49]. They have biological activities and antibacterial, antifungal, and anti-cancer effects [50-52] and catalytic properties [16, 17]; non-toxic nature and high quantum efficiency [18, 53]; disinfectant capacity [54, 55]; stability [56]; water purification properties [57]. Silver-based nanomaterials have antimicrobial and antiseptic effects by producing reactive oxygen species (ROS) and are currently used to treat COVID-19 patients [6].

Although these nanoparticles have not yet been definitively considered for the treatment of SARS-CoV-2, given their previous therapeutic effect against some viruses such as HIV, influenza, hepatitis B, and RSV and neuro-viruses, hopes for its use against SARS kept alive [58]. AGNPs are synthesized by physical, chemical, and biological methods, but the biological method is more environmentally friendly and safer [59]. So far, four types of AGNP have been reported as treatment candidates:

1. Glutathione-capped silver sulfide nanoclusters (GSHAg2S NCs)

2. PVP-coated silver nanomaterials (PVP-AgNMs), which include silver nanowires (AgNWs) and silver nanoparticles (AgNPs)

3. Silver nanoparticle-anchored graphene oxide nanoparticles (GO-AgNPs)

4. PDDA-coated PVP-functionalized graphene oxide-silver nanocomposites (PDDA-PVP-GO-AgNCs) [60]

Their main mechanism is not yet known for sure, but AGNPs inhibit the entry of viruses and also prevent the formation of free radicals in the interaction with biological molecules. They also damage cellular DNA and RNA. A small number of AGNPs have antiviral properties against beta coronavirus [61]. Ag + ion reduces oxidative stress, induces antibody response and cytokine production, and inhibits viral RNA synthesis. It also binds to the gp-120 subunit glycoprotein of the virus and inactivates the virus before binding to the host $[1,6,23]$.

Continuous $\mathrm{Ag}+$ production is important for therapeutic effect [62]. The pseudovirus entry assay test showed that AGNPs interfered with the entry of the virus. AGNPs bind to proteins on the surface of the virus that is rich in sulfhydryl groups. AGNPs cause the breakdown in disulfide bonds, and the proteins become unstable. As a result, they are effective against virus infection because disulfide bonding is very 
important in binding the SARS-CoV-2 virus protein spike to the ACE2 receptor. AGNPs can also be useful in killing intracellular viruses by interacting with viral nucleic acids [58]. They have almost no specific toxicity and can be safely used in studies [63]. The existing hypothesis attributes AGNP toxicity to the direct binding of metal to the surface of a viral protein [60]. ROS production can also be effective in toxicity. Toxicity is concentration dependent (usually seen at concentrations above $20 \mathrm{ppm}$ ), and a series of surface changes can prevent metal surfaces from attaching directly to cells to reduce toxicity. Toxicity also depends on the type of cell and the type of AGNPs and their size. So the smaller particles cause more contact surface with the protein and create more toxicity (AGNPs with a size of $2 \mathrm{~nm}$ are toxic even at a concentration of $2 \mathrm{ppm}$ ). If AGNPs be improperly disposed of, they can have detrimental effects on the destruction of the ecosystem. So we have to have a proper protocol for disposal. The greatest effect of AGNPs is seen in the diameter range of 2 to $15 \mathrm{~nm}$. Coated or capped AGNPs are better than simple AGNPs because they are both more stable and less agglomerated and their cytotoxicity is reduced [58].

The therapeutic effect of oral inhalation of AGNPs: Inhalation of colloidal silver solution fights respiratory infections, which is very important for oral inhalation of colloidal nanoparticles to determine the level of minimum inhibitory concentration (MIC) $[6,64,65]$.

\section{Gold Nanoparticles (AuNP)}

AuNP is used to identify DNA sequences, proteins, bacteria, and viruses and usually has antiviral and antibacterial effects in cancer studies. AuNP activates GNR-50PPP-SSRNA immunity through nanocomplexes, which reduces the replication of viruses, including influenza H1N1 virus, by regulating the expression of IFN- $\beta$ and other IFN stimulated genes (ISGs) [66]. AuNP hyaluronic acid and IFN complex are used for the targeted treatment of hepatitis $\mathrm{C}$ infection [67]. Highly nanodispersed quasispherical AuNP inhibits HSV and is very safe, does not induce resistance, and also has good antiviral properties [68]. AuNP suppresses HIV, influenza, and HSV [69, 70]. AuNP improves the inflammatory response by reducing the expression of interleukin IL1, IL6, TNF- $\alpha$, INF- $\gamma$, and nitric oxide synthetase [22, 24].

AuNPs have good biocompatibility and, if used in vaccine production, stimulate the immune system well and are easily distributed through lymph nodes in the body and activate CD8 + (T killer cell mediated). They are also used for intranasal distribution [24]. They also have the potential to detect viruses as well as antiviral effects, and because of their stable nature, further studies are not useless [71]. Even though there is no authoritative remedy for COVID19 , controlling excessive inflammation or cytokine storms can help treat patients. IL-6, in specific, plays a critical part in causing extreme side effects and harm, so neutralizing and reducing its level decreases the cytokine storm [72, 73]. Cytokine storm, which is accompanied by excessive inflammation, can put an individual with COVID-19 in a critical circumstance. In truth, this storm of cytokines disturbs the functioning of the immune system. Looking at patients conceded to the ICU who involved serious side effects of the infection, we discover that the level of IL-2, IL-7, IL-10, TNF- $\alpha$, and granulocyte-colony-stimulating factor is higher than ordinary. There is also an increment within the systemic level of IP-10, monocyte chemoattractant protein-1 (MCP-1), and macrophage incendiary protein-1 A (MIP-1A) in COVID-19 patients $[74,75]$. So we can say that cytokine storms can increment the risk of death [75]. Finally, we can say AuNPs may affect COVID-19 due to their reducer effect on the expression of cytokines like IL1, IL6, TNF- $\alpha$, and INF- $\gamma$ and inhibiting the cytokine storm.

\section{Gold-Silver Hybrid NP}

Combined gold and silver nanoparticles could be a therapeutic strategy to prevent coronavirus. They are a type of core-shell heterostructure nanocrystals used today in various fields such as decomposition, optical devices, electrical devices, and acoustic imaging. Continuous $\mathrm{Ag}+$ release is very important in the therapeutic response. As the number of viruses increases, more reactive oxygen species (ROS) are produced, causing the silver shell to oxidize at the Au/ AgNP level. As a result, it releases $\mathrm{Ag}+$, which enhances its antiviral activity, and these results encourage us to treat coronavirus [62].

\section{Copper Nanoparticles}

Copper is an essential trace element in the body and the need for protecting DNA from oxidative stress. The role of copper in the pathophysiology of the coronavirus was discussed in our previous work in detail [47]. Briefly, with oxide iodide and sulfide forms, it has antiviral activity against herpes simplex, influenza H1N1, and human neuro virus [76]. The controlled release of copper ions, which is possible by the nanosystem, is the main cause of the antimicrobial and antiviral effects. With the controlled release of copper ions, the production of ROS species is also regulated [77]. Copper has activity against SARS-CoV-2 by three mechanisms: (1) damaging virus membrane and destruction of DNA and RNA, (2) generating reactive oxygen species (ROS) that kills virus, and (3) interfering with important and functional proteins [78-87]. It is hypothesized that an increase in copper levels is related to the body's physiological response to inflammation [88]. Copper may raise ceruloplasmin levels, improving the human body's response to inflammation. Ceruloplasmin has been proven to help the host defend itself by balancing 
the excessive levels of ferritin [89]. Andreou et al. in their study proposed combining the five medicines including remdesivir (RDV), copper, $\mathrm{N}$-acetylcysteine (NAC), NO, and colchicine as a possible antiviral therapy for SARS-CoV-2. NAC may prevent the host cells from excess toxicity of copper, but NAC reduces the absorption of copper. However, a combination of copper with NAC could be used to decrease the RNA levels of the virus in the early stage of infection. Also, combination therapy of copper, NAC, RDV (as antiviral agents), NO (as pulmonary vasodilation), and colchicine (as cytokine storm inhibitor [90]) could decrease or even stop the infection [91]. So it may be suggested that copper nanoparticles may also affect the pathophysiology of COVID-19 due to their impression on ROS production.

\section{Quantum Dots}

Nanocrystals are semiconductor materials with a size of 2 to $10 \mathrm{~nm}$. Used in cell labeling and image recognition and tracking and includes carbon, silver, gold, $\mathrm{CdSeS} / \mathrm{ZnS}$, etc. [92]. In combination with fluorescent samples, it is also used for continuous fluorescence detection and imaging in a series of cellular processes [93]. Unfortunately, their antivirus use is limited. GSH (glutathione)-coated telluride cadmium (Cd) TeQds alter PRV surface proteins, preventing the virus from entering the host cell [94].

Curcumin-stabilized cationic carbon dots (CCM-CDots) alter the structure of the virus's surface proteins, thus suppressing the synthesis of the negative strand of an RNA virus and preventing the virus entry through ROS generation. As a result, they stimulate the production of ISGs as well as pro-inflammatory cytokines [22, 95].

Zirconium QDs are also more sensitive to corona detection than the ELISA method. QDs can be very effective, and on the other hand, one strategy is to cover the therapeutic molecules on the QDs and introduce this product into the body. The benefit of this is that the drug can slowly release the active ingredient in the body [96].

\section{Metal-Grafted Graphene Oxide (GO)}

It is a carbon atom with a thickness of one atom located in a hexagonal lattice in two dimensions [97] and is used as an agent against bacteria and anti-cancer effect [98]. Metalgrafted graphene oxide has an antimicrobial effect and is used with metals such as silver, iron, zinc, and copper or with photocatalysts such as $\mathrm{MnS} 2, \mathrm{CdS}$, and TiO2[77]. GO nanocomposites with AGNP provide better antiviral activity than GO alone or even AG alone [99]. Antiviral activity of silver graphene (GO-Ag) oxide nanocomposites against enveloped and non-enveloped viruses has been reported [1].

\section{Zinc Oxide}

It has significant antimicrobial activity. The role of zinc in the pathophysiology of coronavirus only and combination with agents such as hydroxychloroquine was discussed in our previous work [47]. Zinc-containing compounds have recently been observed to have antiviral activity against SARS-CoV-2. These compounds act on the virus by binding to the virus and destroying the viral coat, as well as inhibiting viral protease and polymerase. In particular, hesperidinmediated zinc nanoparticles bind well to the main protease of SARS-CoV-2 and act on the site of action on the ACE2 receptor and inhibit virus entry. Zinc oxide nanoparticles are well absorbed and inexpensive. They are also low in toxicity and safe [100]. Zinc has an antiviral effect through a series of processes such as the effect on binding, penetration, infection, uncoating, and replication of the virus [101]. Since zinc is a membrane stabilizer, it can directly inhibit virus entry into the host cell [102]. Zinc salts can have an antiviral effect on SARS-CoV-2 by inhibiting virus entry and polyprotein processing or inhibiting RNA-dependent RNA polymerase (RdRP) activity [25, 103]. Zinc stimulates metallothioneins (metal-binding proteins that can regulate zinc homeostasis and reduce heavy metal toxicity [104]) to release zinc into the cytoplasm, decreases oxidative stress caused by RSV and influenza, and maintains a state of cellular redox [105]. The entry of the virus into the cell activates the NF-k $\beta$, which can cause a cytokine storm in the patient and increase the ARD [106, 107]. Zinc can suppress kappa kinase activity, thus inhibiting NF-k $\beta$ signaling and producing fewer pro-inflammatory cytokines $[103,108,109]$. Inhibition of NF-k $\beta$ also increases the antiviral effect of IFN. Also, this dietary intervention with zinc in appropriate concentrations can increase enterocyte stores and improve gastrointestinal symptoms caused by the SARS-CoV-2 virus [103]. Zinc is involved in the production of IL-12 and IFN and also increases IL-12 production by stimulating macrophages, and IL-12 can activate natural killers and T cytotoxic cell. Although zinc has many benefits, high doses of zinc over 6 weeks can disrupt activity and neutrophils, thereby suppressing immunity, and there is a concern about long-term use of zinc. Zinc has good antioxidant, anti-inflammatory, and immune regulatory activity, thus protecting the body against the virus. Given all this, zinc can be considered a good option to deal with SARS-CoV-2 [104]. Briefly, negatively charged zinc oxide ZnO-MNSs trap viruses and prevent them from entering corneal fibroblasts that are the target of HSV1 infection. It can also prevent the virus from spreading [110]. Zinc combined with pyrithione interferes with SARS-CoV-2 RNA replication in cell culture, thus preventing it from replicating $[25,26]$. Also in silico studies were done to obtain the best target for treatment. According to Mohamed Hamdi's study in 2021, Zn oxide NPs with 
a high degree of purity and crystallinity were successfully produced. A putative interaction between $\mathrm{ZnO}$ NPs and the ACE2 receptor as a COVID-19 target has been predicted using in silico molecular docking. In CCD-19Lu human lung fibroblasts, a dose-dependent cellular absorption of $\mathrm{ZnO}$ NPs was achieved. The findings point to the disclosed ZnO NPs' potential for respiratory tract infection outbreaks, suggesting that they could be used alone or in combination with other pharmacologically effective horizons for further investigation and technological transfer [111]. Quercectin (a ubiquitous natural flavonoid) having anti-inflammatory, antiviral, anti-proliferative, anti-oxidative, anti-bacterial, and anti-cancerous activity is a zinc ionophore and prevents the virus from entering the cells. So the combination of zinc and quercetin could be against COVID-19 in two different ways: (a) quercetin inhibits entry of virus and (b) zinc inhibits viral transcription [112]. Also, hydroxychloroquine (HQ) is a zinc ionophore, increases the intracellular concentration of zinc, and so increases the effect of zinc on the RdRP of the virus [113]. The antiviral activity of HQ has been interested recently and HQ is a candidate for the treatment of COVID-19. However, HQ has not had any effects on some viruses including influenza in clinical studies. HQ also reduces the acidity of the endosomes so the release of viruses into the cytoplasm will be prevented. The combination of HQ and zinc might be beneficial in the treatment of COVID-19 [114].

\section{TPNT1}

TPNT1 is the name of the colloidal aqueous solution containing Au-NP (1 ppm), Ag-NP (5 ppm), ZnO-NP (60 ppm), and $\mathrm{ClO}_{2}(42.5 \mathrm{ppm})$ with +32.81 zeta potential. In plaque reduction assay, the number of plaques was significantly decreased with the 100-fold diluted TPNT1 containing $0.01 \mathrm{ppm}$ Au-NP, 0.05 ppm Ag-NP, 0.6 ZnO$\mathrm{NP}$, and $0.425 \mathrm{ppm} \mathrm{ClO}_{2}$. The $\mathrm{IC}_{50}$ of TPNT1 was calculated $143 \pm 15.5$-fold dilution. It has been determined that 93.5-100\% of plaque formations of widespread SARSCoV-2 strains (NTU03, NTU14, and NTU16) could be inhibited by TPNT1. It has been observed that the viral replication and also viral nucleoprotein expression in H1975ACE2 cells could be inhibited by TPNT1. Better inhibition of SARS-CoV-2 replication occurred when SARS-CoV-2 was pre-incubated by diluted TPNT1. According to results from ELISA assay using ACE2-Fc-biotin and spike protein, TPNT1 could inhibit the binding of SARS-CoV-2 spike protein to ACE2 receptors. After receptor binding, syncytium formation is an important step for entry of the virus. Results show that syncytium formation has an obvious reduction by using TPNT1. As we say above, TPNT1 may be a prophylactic option for SARS-CoV-2 and its side opportunistic infection. More studies are needed for better knowledge about these metal nanoparticle compounds [115].

\section{Vanadium}

It is a versatile metal and in various combinations and can be effective in treating diseases such as diabetes and even cancers. Vanadium compounds, for example, affect the body's immune system by stimulating and activating $\mathrm{T}$ cells. Vanadium polyoxide clusters have a good antiviral effect. Also, due to their nuclear properties, they can be a suitable contrast agent that can be used in imaging and better detection of radiological images [116]. Vanadium-based drugs are considered today because they are both less toxic and can have biological activities such as anti-diabetic and anti-cancer properties [117]. Due to vanadium compounds stimulate and activate $\mathrm{T}$ cells, they may improve the immune system against coronavirus.

\section{Gallium}

An elderly woman with acute respiratory failure, who was diabetic, with COVID-19 infection has been evaluated. The gallium scintigraphy in this patient demonstrated a higher level of gallium uptake on the right mastoid with focal intense, which means she had right mastoiditis; however, low level of gallium uptake in lung tissue had been observed even though COVID-19-related pneumonia was getting worse. Although gallium scintigraphy is effective to identify lung infections, gallium is not effective to COVID19-related lesions in the lung and there is no relation between Ga uptake in the lung and COVID-19-related lung disorders [118]. On the other hand, there is some evidence that gallium has shown both anti-inflammatory and antiviral activity due to its chemical similarity to $\mathrm{Fe}^{3+}$ and zinc. There are three hypotheses that show gallium maltolate GaM could have antiviral activity against COVID-19. One of them is that $\mathrm{Ga}$ could compete with zinc and as it is known that $\mathrm{Zn}$ is essential for COVID-19 entry to cells; another theory is that $\mathrm{Ga}$ could compete with iron ions, and it can cause iron deprivation; iron being vital for the replication of the virus means that Ga could be effective $[119,120]$. And at last, it is observed that gallium has an anti-inflammatory effect which is effective against hyperinflammatory signs observed in harsh cases of COVID-19 patients which is similar to septic shock [121, 122]. GaM inhibited replication of virus dose dependently with a concentration of $14 \mu \mathrm{M}$, which replication inhibited by $50 \%$ [123].

\section{Bismuth}

According to biochemistry effects of SARS-COV-2 Nsp13, it has shown that Nsp13 has both nucleoside triphosphate 
hydrolase (NTPase) and RNA helix unwinding activity. The presence of some divalent metal ions is vital for NTPase and also helix unwinding activity of SARS-COV-2 nsp13. For example, some of these ions such as $\mathrm{Mg}^{2+}, \mathrm{Mn}^{2+}, \mathrm{Zn}^{2+}$, and $\mathrm{Ca}^{2+}$ have a supportive effect on ATPase activity of nsp13; however, $\mathrm{Mg}^{2+}$ has the highest efficacy on ATPase activity. However, if $\mathrm{Mg}^{2+}$ concentration is more than $2 \mathrm{mmol} / \mathrm{L}$, it has an inhibitory effect on ATPase activity. The effects of three bismuth salts on nsp13 activity have been evaluated. Three bismuth salts including bismuth potassium citrate (BPC), ranitidine bismuth citrate (RBC), and bismuth citrate (BC) which are used in gastrointestinal diseases. All RBC, $\mathrm{BPC}$, and BC have strong dose-dependent Nsp13 inhibitory effects. However, BC had a less inhibitory effect. So it has been seen that these drugs could inhibit both helix unwinding and ATPase activity of SARS-CoV-2 nsp13 [27]. Nsp enzyme is essential for replication of SAR-CoV-2. This enzyme has zinc-binding domains on its structure and bismuth (III) has an inhibitory effect on this enzyme. Based on the previous analysis, SARS-CoV-2 helicase has three canonical zinc fingers [124]. Ranitidine bismuth citrate can bind to Nsp13 and separate zinc from zinc-binding domains of the enzyme [125]. Bismuth citrate has shown potent anti-SARS-Cov-2 activity both in vitro and in vivo, and the affinity to infected cells was high with an index of 975 . $\mathrm{RBC}$ is not effective in replication of the virus at the preincubation level; however, viral load will be decreased by 2 logs when RBC adds in co-incubation and post-entry-level, which means this drug has a function in the viral entry level [125]. Bismuth alone is not as effective as RBC, and also RBC had much more affinity to bismuth. An 85-year-old man with Crohn's disease who has diarrhea problem in the last 10 days of his visit was evaluated. He also complained about his debilitating cough problems and 5-day regimen of azithromycin prescribed by his primary physician, which was not effective. So he was also suspicious of COVID-19, and while he was waiting for the results of his laboratory tests, he was prescribed with oral $525 \mathrm{mg} \mathrm{2-4}$ times a day bismuth subsalicylate (BSS), and in the first $6 \mathrm{~h}$ of therapy, diarrhea problems improved. Results of the laboratory tests demonstrated that he was COVID-19 positive. After 6 days of BSS therapy, he had improvements in cough and diarrhea. So BSS could have antiviral activity because it can potentially inhibit severe acute respiratory syndrome coronavirus helicase adenosine triphosphatase [126].

\section{Titanium}

Different effects of titanium complexes have been evaluated (antibacterial effects, antifungal effects, and its effect on SARS-CoV-2). Some Schiff base complexes of titanium (HNP-Hn-HNPH2 complex) in silico studies showed better affinity and anti-retroviral activity than standard hydroxychloroquine. It has evaluated that the titanium complex had the most affinity to SARS-CoV-2 main protease (6LU7), and also this ligand is non-carcinogenic and it does not inhibit P-glycoprotein [127].

\section{Palladium}

The affinity of three different complexes of Pd to the main protease of SARS-CoV-2 has been evaluated, and the docking energy of these three complexes was significantly more than chloroquine and hydroxychloroquine, which means $\mathrm{Pd}$ complexes have a much better affinity [128].

The data are summarized in Table 1.

\section{Discussion}

In our previous study, we discuss the roles of trace elements and electrolytes in the pathophysiology of COVID19 . We discovered that changes in electrolytes or trace elements in the body affect the pathophysiology of COVID-19 [28]. Here the important findings were presented in Table 1. Abundant zinc has a good effect due to its antiviral property $[129,130]$, but increasing iron has a bad effect because it rolls in viral replication [131, 132]. COVID19 patients showed both hypokalemia and hyponatremia, and we know that sodium and potassium are involved in many functions in the body, and their changes may cause some dysfunctions [133, 134]. Some other metals and nutrition were discussed in the previous study. Now we studied heavy metals and their salts or nanoparticles in this research. We demonstrated that Ag nanoparticles inhibit virus entry, reduce oxidative stress, and inhibit viral RNA synthesis $[1,6,23]$. Au nanoparticles reduce the expression of some cytokines like IL1, IL6, TNF- $\alpha$, and INF- $\gamma$, so they might be useful in COVID-19 patients to prevent cytokine storm $[22,24,75]$. A combination of silver and gold nanoparticles (gold-silver hybrid NPs) provides a continuous release of $\mathrm{Ag}^{+}$and might have better effects compare to each one alone [62]. Copper nanoparticles have a regulatory effect on ROS production and so might influence the pathophysiology of COVID-19 [77]. Metallic quantum dots can be produced from some metals. GSHcoated telluride cadmium (Cd)TeQds can prevent some viruses from entering [94]. Zirconium QDs are used for the detection of coronavirus, and they are more susceptible than ELISA [96]. Also, silver graphene (GO-Ag) oxide has shown antiviral effects against enveloped and non-enveloped viruses even more than $\mathrm{Ag}$ alone [1, 99]. Vanadium can stimulate the activation of T cells [116], and bismuth has an inhibitory effect on helix unwinding and ATPase activity of SARS-CoV-2 nsp13 [27], so these metals might be useful in the treatment of COVID-19. About gallium 
Table 1 Data summary

\begin{tabular}{|c|c|c|}
\hline Metals and NPs & Target & Action \\
\hline $\mathrm{AgNp}$ & The virus itself and entry of the virus & $\begin{array}{l}\text { AGNPs inhibit the entry of the virus and prevent the formation of free } \\
\text { radicals and also have an antiviral effect on beta coronavirus [1]. Ag } \\
\text { binds to the gp- } 120 \text { subunit glycoprotein of the virus and inactivates } \\
\text { the virus before binding to the host [2-4] }\end{array}$ \\
\hline $\begin{array}{l}\text { Silver grafted graphene } \\
\text { oxide }(\mathrm{GO})+\end{array}$ & - & $\begin{array}{l}\text { GO nanocomposites with AGNP provide better antiviral activity than } \\
\text { GO alone or even AG alone [5] }\end{array}$ \\
\hline AuNP & Cytokines and immune response of the body & $\begin{array}{l}\text { AuNps may affect COVID-19 due to their reducer effect on the expres- } \\
\text { sion of cytokines like IL1, IL6, TNF- } \alpha \text {, and INF- } \gamma \text { and inhibiting the } \\
\text { cytokines storm }[6,7] \text {. They also activate CD }+ \text { cells [6] }\end{array}$ \\
\hline Vanadium & The immune response of the body & $\begin{array}{l}\text { Vanadium compounds stimulate and activate } \mathrm{T} \text { cells; they may improve } \\
\text { the immune system against coronavirus [8] }\end{array}$ \\
\hline Copper nanoparticles & Effect of the virus on the body & $\begin{array}{l}\text { Copper nanoparticles affect the pathophysiology of COVID-19 due to } \\
\text { their impression on ROS production [9] }\end{array}$ \\
\hline Zinc oxide & Replication of virus & $\begin{array}{l}\text { Zinc combined with pyrithione that interferes with SARS-CoV-2 RNA } \\
\text { replication in cell culture, thus preventing it from replicating }[10,11]\end{array}$ \\
\hline Bismuth & Replication of virus & $\begin{array}{l}\text { Bismuth compounds inhibit both helix unwinding and ATPase activity } \\
\text { of SARS-CoV-2 nsp13 [12]. Bismuth citrate has shown potent anti- } \\
\text { SARS-Cov-2 activity both in vitro and in vivo [13] }\end{array}$ \\
\hline Gallium & $\begin{array}{l}\text { 1. Entry and replication of virus } \\
\text { 3. Immune response of the body }\end{array}$ & $\begin{array}{l}\text { There are three hypotheses: } \\
\text { 1. Ga could compete with zinc and as it is known } \mathrm{Zn} \text { is essential for } \\
\text { COVID-19 entry to cells } \\
\text { 2. Ga could compete with iron ions and it can cause iron deprivation } \\
\text { since iron is vital for the replication of the virus }[14,15] \\
\text { 3. Gallium has an anti-inflammatory effect which is effective against } \\
\text { hyperinflammatory signs }[16,17]\end{array}$ \\
\hline Zirconium quantum dots & Detection of virus & $\begin{array}{l}\text { They are more sensitive to corona detection than the ELISA method } \\
\text { [18] }\end{array}$ \\
\hline Titanium & - & $\begin{array}{l}\text { Titanium complex had the most affinity to SARS-CoV-2 main protease } \\
\text { (6LU7) and also this ligand is non-carcinogenic and it does not inhibit } \\
\text { P-glycoprotein [19] }\end{array}$ \\
\hline Palladium & - & $\begin{array}{l}\text { Three different complexes of Pd have an affinity to the main protease of } \\
\text { SARS-CoV-2 [20] }\end{array}$ \\
\hline
\end{tabular}

there are two ideas, some studies believe that gallium has an anti-inflammatory and antiviral activity against SARSCoV-2 and inhibits viral replication [119-123], but other studies believe that there is no relation between gallium uptake and COVID-19 related disorders [118]. Palladium and some Schiff base complexes of titanium have an affinity to the main protease of SARS-CoV-2, so they may be useful in vaccine production $[127,128]$. There is no sufficient information about toxicity and the adverse effects of metal nanoparticles. The toxicity of nanoparticles depends on some factors including type, shape, size, purity, administration route, and the time of exposure to metal nanoparticles. It has known that spherical metal nanoparticles are non- or less toxic than other shapes. The data of studies about toxicity and adverse effects of metal nanoparticles are not enough or may be sometimes consistent. So more research is needed for sufficient and reliable information about toxicity of metal nanoparticles [115]. Considering the effects of heavy metals and their products like nanoparticles and quantum dots, preventing and treatment of
COVID-19 seems useful and might help us better control the disease.

\section{Conclusion}

In the present study, by reviewing the available articles, we inquire about the effects of heavy metals and their other forms, including nanoparticles, quantum dots, and salts, to see if they have roles in the pathophysiology of COVID-19 and which one is more effectual. We observed that some metals or their other forms have good effects on SARSCoV-2 and its disease COVID-19 and can improve patients. More studies and clinical assessments need more information about the effects of metals on COVID-19 to decide on using them in prevention or treatment lines.

Author Contribution Conception and design of the study: F.N. and M.T.; acquisition of data, analysis, and interpretation of data: A.B., 
F.N., H.N., and F.N.; drafting the article: A.B. and F.N.; revising the article critically for important intellectual content: M.T., M.A., S.H., A.F and F.N.; final approval of the version to be submitted: M.T. and F.N.

Funding This work was support financially by Hamadan University of Medical Sciences, Hamadan, Iran.

Data Availability All data are available via the corresponding author.

Code Availability Not applicable.

\section{Declarations}

Ethics Approval This study has been approved by the Ethics Committee of Hamadan University of Medical Sciences. Hamadan, Iran (IR. UMSHA.REC.1400.379).

Conflict of Interest The authors declare no competing interests.

\section{References}

1. Nikaeen G, Abbaszadeh S, Yousefinejad S (2020) Application of nanomaterials in treatment, anti-infection and detection of coronaviruses. Nanomedicine 15(15):1501-1512

2. Nafie M (2020) Coronavirus mutates into 40 strains. How this changes the pandemic outlook: experts. Al Arabiya English. https://english.alarabiya.net/en/features/2020/03/27/Coronavirusmutates-into-40-strains-How-this-changes-the-pandemic-outlo ok-Exp

3. Mainardes RM, Diedrich C (2020) The potential role of nanomedicine on COVID-19 therapeutics. Future Science. Ther Deliv 11(7):411-414

4. Fan Y, Zhao K, Shi Z-L, Zhou P (2019) Bat coronaviruses in China. Viruses 11(3):210

5. Schoeman D, Fielding BC (2019) Coronavirus envelope protein: current knowledge. Virol J 16(1):1-22

6. Das C, Paul SS, Saha A, Singh T, Saha A, Im J et al (2020) Silver-based nanomaterials as therapeutic agents against coronaviruses: a review. Int J Nanomed 15:9301

7. Belouzard S, Millet JK, Licitra BN, Whittaker GR (2012) Mechanisms of coronavirus cell entry mediated by the viral spike protein. Viruses 4(6): 1011-1033

8. Zhang B, Zhou X, Zhu C (2020) Immune phenotyping based on neutrophil-tolymphocyte ratio and IgG predicts disease severity and outcome for patients with COVID-19. Front Mol Biosci 2020. Front Mol Biosci 7:157

9. Yi Y, Lagniton PN, Ye S, Li E, Xu R-H (2020) COVID-19: What has been learned and to be learned about the novel coronavirus disease. Int J Biol Sci 16(10):1753

10. Skalny AV, Lima TRR, Ke T, Zhou J-C, Bornhorst J, Alekseenko SI et al (2020) Toxic metal exposure as a possible risk factor for COVID-19 and other respiratory infectious diseases. Food Chem Toxicol 146:111809

11. Wang L, Wang Y, Ye D, Liu Q (2020) A review of the 2019 novel coronavirus (COVID-19) based on current evidence. Inter J Antimicrob Agents 55(6):105948

12. Rodriguez-Morales AJ, Cardona-Ospina JA, Gutiérrez-Ocampo E, Villamizar-Peña R, Holguin-Rivera Y, Escalera-Antezana JP et al (2020) Clinical, laboratory and imaging features of
COVID-19: a systematic review and meta-analysis. Travel Med Infect Dis 34:101623

13. Wu D, Wu T, Liu Q, Yang Z (2020) The SARS-CoV-2 outbreak: what we know. Int J Infect Dis 94:44-48

14. King AM, Lefkowitz E, Adams MJ, Carstens EB (2011) Virus taxonomy: ninth report of the International Committee on Taxonomy of Viruses: Elsevier

15. Patra JK, Das G, Fraceto LF, Campos EVR, del Pilar R-T, AcostaTorres LS et al (2018) Nano based drug delivery systems: recent developments and future prospects. J Nanobiotechnol 16(1):1-33

16 Bhosale MA, Bhanage BM (2015) Silver nanoparticles synthesis characterization and their application as a sustainable catalyst for organic transformations. Curr Org Chem 19(8):708-27

17. Jiang Z-J, Liu C-Y, Sun L-W (2005) Catalytic properties of silver nanoparticles supported on silica spheres. J Phys Chem B 109(5):1730-1735

18. Basheer NS, Kumar BR, Kurian A, George SD (2013) Silver nanoparticle size-dependent measurement of quantum efficiency of rhodamine 6G. Appl Phys B 113(4):581-587

19. Ianevski A, Yao R, Fenstad MH, Biza S, Zusinaite E, Reisberg $\mathrm{T}$ et al (2020) Potential antiviral options against SARS-CoV-2 infection. Viruses 12(6):642

20. Wang X, Cao R, Zhang H, Liu J, Xu M, Hu H et al (2020) The anti-influenza virus drug, arbidol is an efficient inhibitor of SARS-CoV-2 in vitro. Cell discovery 6(1):1-5

21. Agostini ML, Andres EL, Sims AC, Graham RL, Sheahan TP, Lu X, et al. (2018) Coronavirus susceptibility to the antiviral remdesivir (GS-5734) is mediated by the viral polymerase and the proofreading exoribonuclease. MBio 9(2):e00221-18

22. Gurunathan S, Qasim M, Choi Y, Do JT, Park C, Hong K et al (2020) Antiviral potential of nanoparticles-Can nanoparticles fight against coronaviruses? Nanomaterials 10(9):1645

23. Alphandéry E (2020) The potential of various nanotechnologies for coronavirus diagnosis/treatment highlighted through a literature analysis. Bioconjug Chem 31(8):1873-1882

24. Dkhil MA, Bauomy AA, Diab MS, Al-Quraishy S (2015) Antioxidant and hepatoprotective role of gold nanoparticles against murine hepatic schistosomiasis. Int J Nanomed 10:7467

25. Te Velthuis AJ, van den Worm SH, Sims AC, Baric RS, Snijder EJ, van Hemert MJ (2010) Zn2+ inhibits coronavirus and arterivirus RNA polymerase activity in vitro and zinc ionophores block the replication of these viruses in cell culture. PLoS Pathogens 6(11):e1001176

26. Sarkar PK, Mukhopadhyay CD (2021) Ayurvedic metal nanoparticles could be novel antiviral agents against SARS-CoV-2. Int Nano Lett 11:197-203

27. Shu T, Huang M, Wu D, Ren Y, Zhang X, Han Y et al (2020) SARS-coronavirus-2 Nsp13 possesses NTPase and RNA helicase activities that can be inhibited by bismuth salts. Virol Sin 35(3):321-329

28. Taheri M, Bahrami A, Habibi P, Nouri F (2021) A review on the serum electrolytes and trace elements role in the pathophysiology of COVID-19. Biol Trace Elem Res 199:2475-2481

29. Moghaddam A, Heller RA, Sun Q, Seelig J, Cherkezov A, Seibert $\mathrm{L}$ et al (2020) Selenium deficiency is associated with mortality risk from COVID-19. Nutrients 12(7):2098

30. Dinh QT, Cui Z, Huang J, Tran TAT, Wang D, Yang W et al (2018) Selenium distribution in the Chinese environment and its relationship with human health: a review. Environ Int 112:294-309

31. Huang Y, Wang Q, Gao J, Lin Z, Bañuelos GS, Yuan L et al (2013) Daily dietary selenium intake in a high selenium area of Enshi, China. Nutrients 5(3):700-710

32. Zhang J, Taylor EW, Bennett K, Saad R, Rayman MP (2020) Association between regional selenium status and reported 
outcome of COVID-19 cases in China. Am J Clin Nutr 111(6):1297-1299

33. Li S, Bañuelos GS, Wu L, Shi W (2014) The changing selenium nutritional status of Chinese residents. Nutrients 6(3):1103-1114

34. He L, Zhao J, Wang L, Liu Q, Fan Y, Li B et al (2021) Using nano-selenium to combat coronavirus disease 2019 (COVID19)? Nano Today 36:101037

35. Hahne JC, Mirchev M, Kotzev I, Lampis A, Valeri N (2017) Biomarkers for monitoring response to therapies and detection of acquired resistance in advanced gastrointestinal cancers. Front Clin Drug Res 4:1-73

36. Hosnedlova B, Kepinska M, Skalickova S, Fernandez C, Ruttkay-Nedecky B, Peng Q et al (2018) Nano-selenium and its nanomedicine applications: a critical review. Int J Nanomed 13:2107-2128

37. Zhang J, Wang X, Xu T (2008) Elemental selenium at nano size (nano-Se) as a potential chemopreventive agent with reduced risk of selenium toxicity: comparison with se-methylselenocysteine in mice. Toxicol Sci 101(1):22-31

38. Khurana A, Tekula S, Saifi MA, Venkatesh P, Godugu C (2019) Therapeutic applications of selenium nanoparticles. Biomed Pharmacother 111:802-812

39. Huang B, Zhang J, Hou J, Chen C (2003) Free radical scavenging efficiency of nano-Se in vitro. Free Radic Biol Med 35(7):805-813

40. Wang Z, Zheng Z, Hu H, Zhou Q, Liu W, Li X et al (2020) A point-of-care selenium nanoparticle-based test for the combined detection of anti-SARS-CoV-2 IgM and IgG in human serum and blood. Lab Chip 20(22):4255-4261

41. Huang C, Wang Y, Li X, Ren L, Zhao J, Hu Y et al (2020) Clinical features of patients infected with 2019 novel coronavirus in Wuhan, China. Lancet 395(10223):497-506

42. Lynch E, Kil J, editors. Development of ebselen, a glutathione peroxidase mimic, for the prevention and treatment of noiseinduced hearing loss. Seminars in Hearing; 2009: () Thieme Medical Publishers 30(1):047-055

43. Kil J, Lobarinas E, Spankovich C, Griffiths SK, Antonelli PJ, Lynch ED et al (2017) Safety and efficacy of ebselen for the prevention of noise-induced hearing loss: a randomised, double-blind, placebo-controlled, phase 2 trial. Lancet 390(10098):969-979

44. Masaki C, Sharpley AL, Cooper CM, Godlewska BR, Singh N, Vasudevan SR et al (2016) Effects of the potential lithiummimetic, ebselen, on impulsivity and emotional processing. Psychopharmacology 233(14):2655-2661

45. Feng G, Zheng KI, Yan Q-Q, Rios RS, Targher G, Byrne CD et al (2020) COVID-19 and liver dysfunction: current insights and emergent therapeutic strategies. J Clin Transl Hepatol 8(1): 18

46. Kono H, Arteel GE, Rusyn I, Sies H, Thurman RG (2001) Ebselen prevents early alcohol-induced liver injury in rats. Free Radical Biol Med 30(4):403-411

47. Taheri M, Bahrami A, Habibi P, Nouri F (2021) A review on the serum electrolytes and trace elements role in the pathophysiology of COVID-19. Biol Trace Elem Res 199:2475-2481

48. Abo-Zeid Y, Ismail NSM, McLean GR, Hamdy NM (2020) A molecular docking study repurposes FDA approved iron oxide nanoparticles to treat and control COVID-19 infection. Eur J Pharm Sci 153:105465

49. Zhang X-F, Liu Z-G, Shen W, Gurunathan S (2016) Silver nanoparticles: synthesis, characterization, properties, applications, and therapeutic approaches. Int J Mol Sci 17(9):1534

50. Daima HK, Navya P, Ranjan S, Dasgupta N, Lichtfouse E. Nanosci Med Vol. 1: Springer Nature; 2020. Vol. 1: Springer Nature
51. Ruiz-Hitzky E, Darder M, Wicklein B, Ruiz-Garcia C, MartínSampedro R, Del Real G et al (2020) Nanotechnology responses to COVID-19. Adv Healthcare Mater 9(19):2000979

52. Prabhu S, Poulose EK (2012) Silver nanoparticles: mechanism of antimicrobial action, synthesis, medical applications, and toxicity effects. Int Nano Lett 2(1):1-10

53. Das TK, Karmakar S, Maiti S, Kundu S, Saha A (2020) Room temperature synthesis of NIR emitting $\mathrm{Ag} 2 \mathrm{~S}$ nanoparticles through aqueous route and its influence on structural modulation of DNA. Spectrochim Acta A Mol Biomol Spectrosc 227:117536

54. Deshmukh S, Patil S, Mullani S, Delekar S (2019) Silver nanoparticles as an effective disinfectant: a review. Mater Sci Eng, C 97:954-965

55. Lu S, Gao W, Gu HY (2008) Construction, application and biosafety of silver nanocrystalline chitosan wound dressing. Burns 34(5):623-628

56. Rao YN, Das SK, Saha A (2012) Room temperature aqueous synthesis of bipyramidal silver nanostructures. J Nanosci Nanotechnol 12(3):2014-2021

57. Singh J, Kumar V, Jolly SS, Kim K-H, Rawat M, Kukkar D et al (2019) Biogenic synthesis of silver nanoparticles and its photocatalytic applications for removal of organic pollutants in water. J Ind Eng Chem 80:247-257

58. Jeremiah SS, Miyakawa K, Morita T, Yamaoka Y, Ryo A (2020) Potent antiviral effect of silver nanoparticles on SARS-CoV-2. Biochem Biophys Res Commun 533(1):195-200

59. Rosa RM, Silva JC, Sanches IS, Henriques C (2017) Simultaneous photo-induced cross-linking and silver nanoparticle formation in a PVP electrospun wound dressing. Mater Lett 207:145-148

60. Galdiero S, Falanga A, Vitiello M, Cantisani M, Marra V, Galdiero M (2011) Silver nanoparticles as potential antiviral agents. Molecules 16(10):8894-8918

61. Du T, Lu J, Liu L, Dong N, Fang L, Xiao S et al (2018) Antiviral activity of graphene oxide-silver nanocomposites by preventing viral entry and activation of the antiviral innate immune response. ACS Appl Bio Mater 1(5):1286-1293

62. Du T, Zhang J, Li C, Song T, Li P, Liu J et al (2020) Gold/silver hybrid nanoparticles with enduring inhibition of coronavirus multiplication through multisite mechanisms. Bioconjug Chem 31(11):2553-2563

63. Burdușel A-C, Gherasim O, Grumezescu AM, Mogoantă L, Ficai A, Andronescu E (2018) Biomedical applications of silver nanoparticles: an up-to-date overview. Nanomaterials 8(9):681

64. Zachar O (2020) Formulations for COVID-19 early stage treatment via silver nanoparticles inhalation delivery at home and hospital. ScienceOpen Preprints 10.14293/S2199-1006.1.SOR-. PPHBJEO.v1

65. Dong Y, Zhu H, Shen Y, Zhang W, Zhang L (2019) Antibacterial activity of silver nanoparticles of different particle size against vibrio natriegens. PLoS One 14(9):e0222322

66. Chakravarthy KV, Bonoiu AC, Davis WG, Ranjan P, Ding H, Hu $R$ et al (2010) Gold nanorod delivery of an ssRNA immune activator inhibits pandemic H1N1 influenza viral replication. Proc Natl Acad Sci 107(22):10172-10177

67. Lee M-Y, Yang J-A, Jung HS, Beack S, Choi JE, Hur W et al (2012) Hyaluronic acid-gold nanoparticle/interferon $\alpha$ complex for targeted treatment of hepatitis C virus infection. ACS Nano 6(11):9522-9531

68. Halder A, Das S, Ojha D, Chattopadhyay D, Mukherjee A (2018) Highly monodispersed gold nanoparticles synthesis and inhibition of herpes simplex virus infections. Mater Sci Eng, C 89:413-421

69. Andresen H, Mager M, Grießner M, Charchar P, Todorova N, Bell N et al (2014) Single-step homogeneous immunoassays 
utilizing epitope-tagged gold nanoparticles: on the mechanism, feasibility, and limitations. Chem Mater 26(16):4696-4704

70. Bowman M-C, Ballard TE, Ackerson CJ, Feldheim DL, Margolis DM, Melander C (2008) Inhibition of HIV fusion with multivalent gold nanoparticles. J Am Chem Soc 130(22):6896-6897

71. Muhammad W, Zhai Z, Gao C (2020) Antiviral activity of nanomaterials against coronaviruses. Macromol Biosci 20(10):2000196

72. Atal S, Fatima Z (2020) IL-6 inhibitors in the treatment of serious COVID-19: a promising therapy? Pharm Med 34(4):223-231

73. Michot J-M, Albiges L, Chaput N, Saada V, Pommeret F, Griscelli F et al (2020) Tocilizumab, an anti-IL-6 receptor antibody, to treat COVID-19-related respiratory failure: a case report. Ann Oncol 31(7):961-964

74. Ruan Q, Yang K, Wang W, Jiang L, Song J (2020) Clinical predictors of mortality due to COVID-19 based on an analysis of data of 150 patients from Wuhan, China. Intensive Care Med 46(5):846-848

75. Fara A, Mitrev Z, Rosalia RA, Assas BM (2020) Cytokine storm and COVID-19: a chronicle of pro-inflammatory cytokines. Open Biol 10(9):200160

76. Ishida $\mathrm{T}$ (2018) Antiviral activities of $\mathrm{Cu} 2+$ ions in viral prevention, replication, RNA degradation, and for antiviral efficacies of lytic virus, ROS-mediated virus, copper chelation. World Sci News 99:148-168

77. Sportelli MC, Izzi M, Kukushkina EA, Hossain SI, Picca RA, Ditaranto $\mathrm{N}$ et al (2020) Can nanotechnology and materials science help the fight against SARS-CoV-2? Nanomaterials 10(4):802

78. Erxleben A (2018) Interactions of copper complexes with nucleic acids. Coord Chem Rev 360:92-121

79. Fujimori Y, Sato T, Hayata T, Nagao T, Nakayama M, Nakayama $\mathrm{T}$ et al (2012) Novel antiviral characteristics of nanosized copper (I) iodide particles showing inactivation activity against 2009 pandemic H1N1 influenza virus. Appl Environ Microbiol 78(4):951-955

80. Horie M, Ogawa H, Yoshida Y, Yamada K, Hara A, Ozawa K et al (2008) Inactivation and morphological changes of avian influenza virus by copper ions. Adv Virol 153(8):1467-1472

81. Novello F, Stirpe F (1969) The effects of copper and other ions on the ribonucleic acid polymerase activity of isolated rat liver nuclei. Biochem J 111(1):115-119

82. Rupp JC, Locatelli M, Grieser A, Ramos A, Campbell PJ, Yi H et al (2017) Host cell copper transporters CTR1 and ATP7A are important for Influenza A virus replication. Virol J 14(1):1-12

83. Sagripanti J-L (1992) Metal-based formulations with high microbicidal activity. Appl Environ Microbiol 58(9):3157-3162

84 Sagripanti J-L, Lightfoote MM (1996) Cupric and ferric ions inactivate HIV. AIDS Re Hum Retrovir 12(4):333-6

85. Sagripanti J-L, Routson LB, Bonifacino AC, Lytle CD (1997) Mechanism of copper-mediated inactivation of herpes simplex virus. Antimicrob Agents Chemother 41(4):812-817

86. Sagripanti J-L, Routson LB, Lytle CD (1993) Virus inactivation by copper or iron ions alone and in the presence of peroxide. Appl Environ Microbiol 59(12):4374-4376

87. Shionoiri N, Sato T, Fujimori Y, Nakayama T, Nemoto M, Matsunaga $T$ et al (2012) Investigation of the antiviral properties of copper iodide nanoparticles against feline calicivirus. J Biosci Bioeng 113(5):580-586

88. Neve J, Fontaine J, Peretz A, Famaey J-P (1988) Changes in zinc, copper and selenium status during adjuvant-induced arthritis in rats. Agents Actions 25(1):146-155

89. Cherukuri S, Potla R, Sarkar J, Nurko S, Harris ZL, Fox PL (2005) Unexpected role of ceruloplasmin in intestinal iron absorption. Cell Metab 2(5):309-319
90. Leung YY, Yao Hui LL, Kraus VB (2015) Colchicine-Update on mechanisms of action and therapeutic uses. Semin Arthritis Rheum 45(3):341-350

91 Andreou A, Trantza S, Filippou D, Sipsas N, Tsiodras S (2020) COVID-19: The potential role of copper and $\mathrm{N}$-acetylcysteine (NAC) in a combination of candidate antiviral treatments against SARS-CoV-2. In Vivo 34(3 suppl):1567-88

92. Michalet X, Pinaud F, Bentolila L, Tsay J, Doose S, Li J et al (2005) Quantum dots for live cells, in vivo imaging, and diagnostics. Science 307(5709):538-44

93. Peer D, Karp JM, Hong S, Farokhzad OC, Margalit R, Langer R (2007) Nanocarriers as an emerging platform for cancer therapy. Nat Nanotechnol 2(12):751-760

94. Du T, Cai K, Han H, Fang L, Liang J, Xiao S (2015) Probing the interactions of CdTe quantum dots with pseudorabies virus. Sci Rep 5(1):1-10

95. Du T, Liang J, Dong N, Lu J, Fu Y, Fang L et al (2018) Glutathione-capped $\mathrm{Ag} 2 \mathrm{~S}$ nanoclusters inhibit coronavirus proliferation through blockage of viral RNA synthesis and budding. ACS Appl Mater Interfaces 10(5):4369-4378

96. Manivannan S, Ponnuchamy K. (2020) Quantum dots as a promising agent to combat COVID-19. Applied organometallic chemistry. 34(10):e5887

97. Ghosal K, Sarkar K (2018) Biomedical applications of graphene nanomaterials and beyond. ACS Biomater Sci Eng 4(8):2653-2703

98. Gurunathan S, Arsalan Iqbal M, Qasim M, Park CH, Yoo H, Hwang JH et al (2019) Evaluation of graphene oxide induced cellular toxicity and transcriptome analysis in human embryonic kidney cells. Nanomaterials 9(7):969

99. Chen Y-N, Hsueh Y-H, Hsieh C-T, Tzou D-Y, Chang P-L (2016) Antiviral activity of graphene-silver nanocomposites against non-enveloped and enveloped viruses. Int J Environ Res Public Health 13(4):430

100. Attia GH, Moemen YS, Youns M, Ibrahim AM, Abdou R, El Raey MA (2021) Antiviral zinc oxide nanoparticles mediated by hesperidin and in silico comparison study between antiviral phenolics as anti-SARS-CoV-2. Colloids Surfaces B: Biointerfaces 203:111724

101. Read SA, Obeid S, Ahlenstiel C, Ahlenstiel G (2019) The role of zinc in antiviral immunity. Adv Nutr 10(4):696-710

102. Pasternak C (1987) A novel form of host defence: membrane protection by $\mathrm{Ca} 2+$ and $\mathrm{Zn} 2+$. Biosci Rep 7(2):81-91

103. Rani I, Goyal A, Bhatnagar M, Manhas S, Goel P, Pal A et al (2021) Potential molecular mechanisms of zinc-and coppermediated antiviral activity on COVID-19. Nutr Res 92:109-128

104. Pal A, Squitti R, Picozza M, Pawar A, Rongioletti M, Dutta AK et al (2020) Zinc and COVID-19: basis of current clinical trials. Biol Trace Elem Res 199:2882-2892

105. Khan NA, Singla M, Samal S, Lodha R, Medigeshi GR (2020) Respiratory syncytial virus-induced oxidative stress leads to an increase in labile zinc pools in lung epithelial cells. Msphere 5(3):e00447-e520

106. Lytton SD, Antiga E, Pfeiffer S, Matthias T, Szaflarska-Poplawska A, Ulaganathan VK et al (2013) Neo-epitope tissue transglutaminase autoantibodies as a biomarker of the gluten sensitive skin disease- dermatitis herpetiformis. Clin Chim Acta 415:346-349

107. de Lemos JA, McGuire DK, Drazner MH (2003) B-type natriuretic peptide in cardiovascular disease. The Lancet 362(9380):316-322

108. Wang P, Wu J, Ma S, Zhang L, Yao J, Hoadley KA et al (2015) Oncometabolite D-2-hydroxyglutarate inhibits ALKBH DNA repair enzymes and sensitizes IDH mutant cells to alkylating agents. Cell Rep 13(11):2353-2361 
109. Prasad AS, Bao B, Beck FW, Sarkar FH (2011) Zinc-suppressed inflammatory cytokines by induction of A20-mediated inhibition of nuclear factor- $\kappa \mathrm{B}$. Nutrition 27(7-8):816-823

110. Antoine TE, Mishra YK, Trigilio J, Tiwari V, Adelung R, Shukla D (2012) Prophylactic, therapeutic and neutralizing effects of zinc oxide tetrapod structures against herpes simplex virus type-2 infection. Antiviral Res 96(3):363-375

111. Hamdi M, Abdel-Bar HM, Elmowafy E, El-Khouly A, Mansour M, Awad GA (2021) Investigating the Internalization and COVID-19 Antiviral Computational Analysis of Optimized Nanoscale Zinc Oxide. ACS Omega 6(10):6848-6860

112. Pawar A, Pal A (2020) Molecular and functional resemblance of dexamethasone and quercetin: A paradigm worth exploring in dexamethasone-nonresponsive COVID-19 patients. Phytother Res 34(12):3085-3088

113. Abd-Elsalam S, Soliman S, Esmail ES, Khalaf M, Mostafa EF, Medhat MA et al (2020) Do zinc supplements enhance the clinical efficacy of hydroxychloroquine?: a randomized, multicenter trial. Biol Trace Elem Res. https://doi.org/10.1007/ s12011-020-02512-1

114. Pal A, Pawar A, Goswami K, Sharma P, Prasad R (2020) Hydroxychloroquine and Covid-19: a cellular and molecular biology based update. Indian J Clin Biochem 35(3):274-284

115. Chang SY, Huang KY, Chao TL, Kao HC, Pang YH, Lu L et al (2021) Nanoparticle composite TPNT1 is effective against SARS-CoV-2 and influenza viruses. Sci Rep 11(1):8692

116. Scior T, Abdallah HH, Mustafa SFZ, Guevara-García JA, Rehder D (2021) Are vanadium complexes druggable against the main protease mpro of sars-cov-2?-a computational approach. Inorg Chim Acta 519:120287

117. Vlasiou MC, Pafiti KS (2021) Screening Possible Drug Molecules for Covid-19. The example of vanadium (III/IV/V) complex molecules with computational chemistry and molecular docking Computational Toxicology.18:100157

118. Zamora E, Valdivia AY, Zalta B, Zuckier LS (2020) [67Ga] Ga-citrate and COVID-19-associated pneumonia: an unexpected absence of uptake. Eur J Nucl Med Mol Imaging 47(9):2207-2208

119. Liu W, Zhang S, Nekhai S, Liu S (2020) Depriving iron supply to the virus represents a promising adjuvant therapeutic against viral survival. Curr Clin Microbiol Repo 7(2):13-19

120. Podsiadlo P, Komiyama T, Fuller RS, Blum O (2004) Furin inhibition by compounds of copper and zinc. J Biol Chem 279(35):36219-36227

121. Colafrancesco S, Alessandri C, Conti F, Priori R (2020) COVID19 gone bad: a new character in the spectrum of the hyperferritinemic syndrome? Autoimmun Rev.19(7):102573

122. Krecic-Shepard ME, Shepard DR, Mullet D, Apseloff G, Weisbrode SE, Gerber N (1999) Gallium nitrate suppresses the production of nitric oxide and liver damage in a murine model of LPS-induced septic shock. Life Sci 65(13):1359-1371

123. Bernstein LR, Zhang L (2020) Gallium maltolate has in vitro antiviral activity against SARS-CoV-2 and is a potential treatment for COVID-19. Antivir Chem Chemother 28:2040206620983780
124. Jia Z, Yan L, Ren Z, Wu L, Wang J, Guo J et al (2019) Delicate structural coordination of the severe acute respiratory syndrome coronavirus Nsp13 upon ATP hydrolysis. Nucleic Acids Res 47(12):6538-6550

125. Yuan S, Wang R, Chan JF, Zhang AJ, Cheng T, Chik KK et al (2020) Metallodrug ranitidine bismuth citrate suppresses SARSCoV-2 replication and relieves virus-associated pneumonia in Syrian hamsters. Nat Microbiol 5(11):1439-1448

126. Wolf DC, Wolf CH, Rubin DT (2020) Temporal improvement of a COVID-19-positive Crohn's disease patient treated with bismuth subsalicylate. Am J Gastroenterol 115(8):1298

127. Uddin MN, Amin MS, Rahman MS, Khandaker S, Shumi W, Rahman MA et al (2021) Titanium (IV) complexes of some tetra-dentate symmetrical bis-Schiff bases of 1,6-hexanediamine: Synthesis, characterization, and in silico prediction of potential inhibitor against coronavirus (SARS-CoV-2). Appl Organomet Chem. 35(1):e6067

128. Haribabu J, Srividya S, Mahendiran D, Gayathri D, Venkatramu V, Bhuvanesh N et al (2020) Synthesis of palladium(II) complexes via Michael addition: antiproliferative effects through ROS-mediated mitochondrial apoptosis and docking with SARSCoV-2. Inorg Chem 59(23):17109-17122

129. Derwand R, Scholz M (2020) Does zinc supplementation enhance the clinical efficacy of chloroquine/hydroxychloroquine to win todays battle against COVID-19? Med Hypotheses 142:109815

130. Skalny AV, Rink L, Ajsuvakova OP, Aschner M, Gritsenko VA, Alekseenko SI et al(2020) Zinc and respiratory tract infections: perspectives for COVID-19 (Review). Int J Mol Med 46(1):17-26

131. Wessling-Resnick M (2018) Crossing the iron gate: why and how transferrin receptors mediate viral entry. Annu Rev Nutr 38:431-458

132. Dalamaga M, Karampela I, Mantzoros CS (2020) Commentary: Could iron chelators prove to be useful as an adjunct to COVID19 treatment regimens? Metabolism 108:154260

133. chen d, Li X, song q, Hu C, Su F, Dai J (2020) Hypokalemia and clinical implications in patients with coronavirus disease 2019 (COVID-19). https://doi.org/10.1101/2020.02.27.20028530

134. Zhang XL, Cai H, Hu JH, Lian JS, Gu JQ, Zhang SY et al (2020) Epidemiological, clinical characteristics of cases of SARS$\mathrm{CoV}-2$ infection with abnormal imaging findings. Int J Infect Dis 94:81-87

Publisher's Note Springer Nature remains neutral with regard to jurisdictional claims in published maps and institutional affiliations. 